\title{
NOTES ON THE PARASITOLOGY, PATHOLOGY AND BIO-PHYSIOLOGY OF SPRINGBOK IN THE MOUNTAIN ZEBRA NATIONAL PARK
}

\author{
by
}

\section{E. YOUNG*, F. ZUMPT**, P. A. BASSON***, B. ERASMUS****, P. A. BOYAZOGLU**** and J. BOOMKER****}

\begin{abstract}
Thirteen species of parasitic metazoa and two protozoa have been identified. Pathological effects are described where applicable. Serological tests for virus diseases were negative but biochemical analyses revealed certain mineral deficiencies. The possible decimating effects of the former are discussed and appropriate guide lines for control suggested.
\end{abstract}

During a preliminary survey in October, 1971 in the Mountain Zebra National Park (M.Z.N.P.) near Cradock, Cape Province, 10 live and eight dead springbok, Antidorcas marsupialis, were captured or culled. These were examined and the necessary specimens collected for subsequent analyses. The results of this preliminary survey can be very briefly summarized as follows:

\section{Endoparasites}

Haemonchus contortus was collected from the abomasum, Cooperioides antidorci, Paracooperia serrata, Nematodirus sp. and Trichostrongylus faculatus from the duodenum, Agriostomum equidentatum from the colon and Cysticercus tenuicollis from the abdominal cavity.

Cooperioides antidorci caused extensive duodenal lesions in some of the animals and it is suspected that this parasite may, under certain circumstances, be responsible for very adverse effects on super-infested springbok. The parasites (small nematodes) were found in numerous small but macroscopically visible glistening cysts. Microscopically it could be seen that many of the duodenal crypts, containing the parasites, had become occluded and cystic. The cystic lesions were present in the mucosa as well as in the submucosa, and in the latter the parasites were in some cases

* Division of Veterinary Services, Kruger National Park, P.O. Box 12, Skukuza.

** South African Institute for Medical Research, Fohannesburg.

*** Division of Veterinary Services, Grootfontein, South West Africa.

**** Veterinary Research Institute, Onderstepoort 
surrounded by considerable granulomatous reaction and fibrosis. In cross section, the helminths have 10 to 14 longitudinal ridges with cross striations.

The aetiology of the abomasal erosions and ulcerations has not yet been established without doubt but it is suspected that these lesions, as well as the mixed cell abomasitis, seen in some animals, might have been due secondarily to haemonchosis.

It is also suspected that endoparasites, such as $C$. tenuicollis and A. equidentatum and possibly others whose migratory patterns are still unknown, while migrating through the liver at some stage of their life cycle, could have been responsible for the lesions frequently seen in this organ. These lesions included localized patches of necrosis and subacute to chronic hepatitis, as well as proliferative and granulomatous reactions and fibrosis in some portal areas. Localized segmental eosinophilic endophlebitis of the portal veins was also observed which strengthens the suspicion of migrating parasites being involved.

\section{Ectoparasites}

The ticks, Hyalomma rufipes, Rhipicephalus glabroscutatum and $R$. e. evertsi and the lice, Linognathus euchore, L. armatus and L. bedfordi parasitised the sampled springbok.

$H$. rufipes caused extensive dermal necrosis and localized, superficial mastitis.in one animal. The other external parasites were not associated with any lesions.

Sarcoptes scabiei, associated with severe mange, has recently been isolated from springbok in the Kalahari Gemsbok National Park (Young and Zumpt, ms.). Springbok in the M.Z.N.P., however, seem to be free of this potentially fatal infestation.

\section{Protozoal, viral and bacterial diseases}

Examination of blood smears revealed a Cytauxzoon sp. (Neitz, pers. $c_{o m m}$.) while mild sarcosporidiosis was diagnosed by microscopic examination of the cardiac musculature of one animal.

Serological tests on serum samples failed to show antibodies against blue tongue, Rift valley fever or Wesselsbron disease.

No specific bacterial diseases were diagnosed although one very sick and debilitated animal suffered from severe, purulent pneumonia and another from otitis externa, both conditions apparently having been due to bacterial infection.

\section{Nutrition, biochemistry and general bio-physiology}

Liver-samples were collected from five adult springbok and analysed for trace-elements according to the techniques used by Boyazoglu, Barrett, Young and Ebedes (1972). The average figures (p.p.m. on wet basis) were: $\mathrm{Mn}(4,8), \mathrm{Cu}(11,8)$, Co $(13,4), \mathrm{Zn}(126), \mathrm{Fe}(183)$ and $\mathrm{Mg}$ (118). 
These results were compared with those obtained from the analyses of liver-samples of three adult springbok from the Kalahari Gemsbok National Park. From these comparisons it appears that relative deficiencies of manganese, cobalt, magnesium and especially of copper may occur in the M.Z.N.P. Values for zinc and especially for iron were, on the contrary, higher for the latter park. When compared with average results obtained from analyses of samples from 250 wild mammals of 16 different species from the Kruger and Etosha National Parks (Boyazoglu, Barrett, Young and Ebedes, 1972), deficiencies of manganese, cobalt, magnesium and especially copper again seem to occur in the M.Z.N.P.

It is suspected that deficiencies of some of these trace elements, notably of copper and cobalt, as well as a possible phosphate deficiency, severe parasitism and inbreeding may be responsible for the apparent smaller size of these springbok, compared to springbok from some places elsewhere in the Republic of South Africa or South West Africa. The macro-element survey has not yet been completed but dental and other skeletal abnormalities observed point towards a possible deficiency of phosphorus. Excessive mineral deposits in the urine of slaughtered animals (in some individuals associated with mucosal haemorrhages of the urinary bladder) suggest the possible excessive intake of dietary calcium which may result in, or aggravate phosphorus deficiency. This supposition, however, still has to be evaluated by further research.

Electrophoretic and other analyses of serum and haemoglobin samples have also not yet been completed but the considerable increase of this population from about 20 individuals (1943) to more than 1200 animals leaves no doubt as to the possibility that a remarkable degree of inbreeding must already be present in these springbok. Pathognomic clinical signs of inbreeding which have during the past few years repeatedly been encountered in an inbred population of springbok in the Warmbaths district of the Transvaal have, however, not yet been observed in springbok of the M.Z.N.P.

\section{General remarks}

Despite the prolific and very successful numerical increase of this population over the past few years, the continued and unrestricted increase of springbok in this relatively small National Park does not seem feasible and may eventually prove disastrous*. Optimal population density has apparently been exceeded and intra and interspecific competition has already become a reality. Excessive concentrations of animals weakened by nutritional deficiencies, parasitism and inbreeding are usually extremely liable to the development of catastrophes and special attention must preferably be paid in the case of this population to the advisability and possibilities of reduction campaigns, the introduction of new genetic material, mineral supplementation and possibly also to periodic and controlled low level anthelmintic treatment via mineral licks. 


\section{Acknowledgements}

We wish to extend our thanks and appreciation to the Director of the National Parks Board for making the study material available. Special thanks are due to Mr. A. M. Brynard and Dr. G. de Graaff, Deputy Director and Assistant Director (Other National Parks) respectively of the National Parks Board, for special arrangements. We also thank all other personnel of the National Parks Board, the Onderstepoort Veterinary Research Institute, the S.A.I.M.R. (ectoparasite research supported financially by the S.A. Medical Research Council) and Mrs. B. Young for their invaluable assistance in collecting and/or examining the sample material.

*Towards the end of 1972, the numbers of springbok were reduced by 700 individuals - Eds.

\section{REFERENCE}

BOYAZOGLU, P. A., E. L. BARRETT, E. YOUNG and H. EBEDES. 1972. Liver mineral analyses as indicator of nutritional adequacy. 2nd World Congress on Animal Feeding, 23-28 Oct., 1972, Madrid, Spain. 